\title{
PRELIMINARY ASSESSMENT OF THE IMPACT OF CULTURE ON UNDERSTANDING CARTOGRAPHIC REPRESENTATIONS
}

\author{
Marcio Augusto Reolon Schmidt, ${ }^{\mathrm{a}}$ André Luiz de Alencar Mendonça, ${ }^{\mathrm{b}}$ Małgorzata Wieczorek ${ }^{\mathrm{c}}$ \\ ${ }^{a}$ Programa de Pós-Graduação da Faculdade de Engenharia Civil, Universidade Federal de Uberlândia, Uberlândia, Minas Gerais, \\ Brazil; marcio.schmidt@ufu.br \\ ${ }^{b}$ Escola Superior de Tecnologia, universidade Estadual do Amazonas, Manaus, Amazonas, Brazil; andremalms@hotmail.com \\ ${ }^{c}$ Department of Geoinformatics and Cartography, University of Wroclaw, Wroclaw, Poland; malgorzata.wieczorek@uwr.edu.pl
}

\begin{abstract}
When users read a topographic map, they have to decode the represented information. This decoding passes through various processes in order to perceive, interpret, and understand the reported information. This set of pro-cesses is intrinsically a question that is influenced by culture. In particular, when one thinks of maps distributed across the internet or representations of audiences from different origins, the chance of efficient communication is reduced or at least influenced. Therefore, there should be some degree of common visual communication, which the symbology of maps can be applied in order to assure the adequate communication of phenomenon being rep-resented on it. In this context, the present work aims at testing which evaluation factors influence the reading of maps, the understanding of space and reasoning of the map user, in particular national topographic maps. The assessment was through internet considering official map representation from Brazil and Poland and questionnaires. The results shown that conventional topographic maps on the same scale are not capable of producing the correct interpretation of the user from another culture. This means that formal training has a direct influence on the quality of the interpretation and spatial reasoning. Those results indicate that high levels of formal training positively influence the reading and interpretation results of the map and that there is no evidence that the specialists with the symbology of their own country have significantly positive results, when compared to those used maps with systematic mapping from another country.
\end{abstract}

Keywords: Culture, Map reading, User issues, topographic map

\section{Introduction}

The distribution of maps over the Internet allows users from around the world to obtain information about any region on their mobile or conventional device. Topographic map has its symbology conventionally defined in each country according to a specific context of use and reading conditions. Although this context has changed radically in recent years, among other reasons, an access capability given by the Internet, the requirements of design solutions to be appropriate to the users' cognitive ability. In this way, these topographic maps can be used at its better use in decision supporting from the representation, especially for the semantic characteristics of the cartographic representation. The problem that is proposed from this context concerns how the reading and interpretation of the maps are affected when these topographic maps are distributed and accessed by users of other countries, unfamiliar with the conventional symbology characteristics used in a map produced in foreign country.

According to MacEachren (1995), the process of map reading is an individual task because several factors influence on this process. Crampton (2001) states that cartography finds a need to know the cognitive, psychological and physical parameters of its users, so do that in an individualized way. The user can understand, learn and re-member the information communicated by the map. The map reading strategy is not independent of the user's cognitive process and influences the strategies or methods used by the map-reader. Individual spatial skills explain some differences in the development of cognitive mapping, such as geometric thinking ability, ability to create spatial relations images at different scales (local to global), to recognize spatial patterns, to perceive three-dimensional characteristics in two dimensions, estimating distances and direction, and integrating routes and reference points (GOODLEDGE, 1993). The internalization of the information contained in the maps, after filtering and internal processing, is stored in the individual's cognitive map of the area. Thus, the spatial knowledge of a region contains several cognitive maps at different scales that are related through reference points (SCHMIDT and DELAZARI, 2013). In the context of cartography, these differences can alter the perception of symbols in the use of any representation, influencing the figure-background separation and the interrelation of symbols on the map and correlating colors and features, such as blue for water bodies and green for vegetation.

Among the many factors that may influence the reading of a cartographic representation are the formal training in cartography presented by Schmidt and Delazari (2013), cognitive and perceptive development (SLOCUM, 1999), and cultural characteristics (TAYEB, 2001; PERKINS, 2004). The way in which the symbols are constructed and interpreted passes through questions related to the culture 
of the environment in which the map is created and used (PERKINS, 2004; 2009; ITO e SANO, 2011; LEE e BUTLER, 2014).

For Roth (2015) culture is the derivation of knowledge and, from a cartography perspective, this means the derivation of more complex concepts supported by map reading, such as the delimitation of hydrographic basins. For Tayeb (2001), the term culture is almost impossible to capture and measure in all its aspects, due to the immateriality of such a complex concept. However, their influence is strongly perceived in people's behavior and reactions in certain contexts. For this author, the model of culture factor implies in the minimalism adopted by researchers to select some aspects of culture selected for studies. In addition to individual variations, there are regional variations within a single country, some of which are not caused by cultural factors. Tayeb (2001) states that culture does not depend exclusively on geographic boundaries but rather on clusters of customs, experiences and experiences that pierce the knowledge form and can be regionalized.

In this context, the process of map construction may also reflect part of the culture in which the cartographer is inserted and, on the other hand, the map reader should be able to adopt a strategy that includes reading the maps produced with a particular visual solution. The user must be able to perceive these differences in the way the symbology of the map is proposed and presented. Finally, any cartographer must understand these differences in user culture and develop strategies to make the map readable to its audience.

This research starts from the premise that cartographic elements common to topographic maps, even with different visual solutions given by the conventions adopted by each country, limit the mapping process without specific training. That is, even if official topographic maps of different countries present similar sets of information, differences in the symbology make it difficult for experienced users to read, interpret and perform simple tasks with maps. This work aims to evaluate, although in a preliminary way, the role of familiarity with visual solution of official topographic maps in the effectiveness of the use of these maps.

\section{Users evaluation}

A questionnaire was published in the Internet with four pieces of topographic maps from Brazil and Poland. It is believed that this number is sufficient to represent the different nuances of the cartographic symbology and could work as a sample to preliminarily evaluate the factors influencing the map reading. In figure 1 , we present two ex-tracts maps of the Brazilian systematic mapping on the 1: 50,000 scale, provided by the Brazilian Institute of Geography and Statistics (IBGE), and two maps of the systematic Polish mapping on the same scale provided by the Institute of Geodesy and Cartography (IGiK). Since language is a major problem for searching in different countries, any textual information such as names of rivers, cities, highways and coordinates has been removed so that a direct identification of the region by any participant is not possible and avoid its influence in the responses.

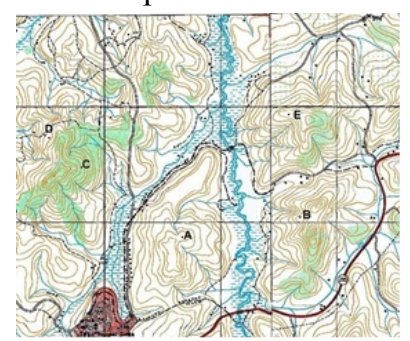

BRAZILIAN MAP

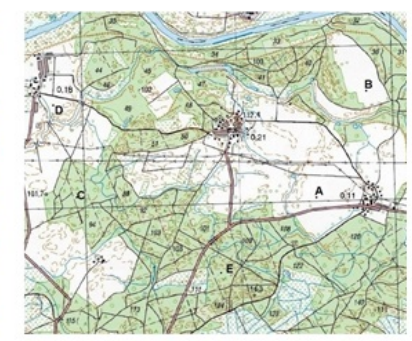

POLISH MAP
Fig. 1. Two map extracts used in the tests. (Source: IBGE and IGiK)

The assesment was performed through common tasks using map such as altitudes estimation, point intervisibility, watershed identification, distance (reading) and relative orientation estimation, geographic features remembrance (interpretation, reasoning and memorization). These questions are based on the map reading steps of Board (1984, cited in Van Elzakker, 2004), which seeks to identify what is in the map area, to estimate quantities, to position it in relation to the surrounding objects, to quantify and delimit a phenomenon among other questions (Table 1).

\begin{tabular}{|c|c|}
\hline Geographic questions & Tasks \\
\hline \multicolumn{2}{|l|}{ Elementary } \\
\hline What is there? & 1. to recognize objects (external identification) \\
\hline At a given place, what is there? & 2. to identify objects (internal identification) \\
\hline At a given place, ho much is there? & 3. to estimate amounts \\
\hline Where is that geographic object? & 4. to locate an object \\
\hline \multicolumn{2}{|l|}{ Intermediate } \\
\hline What is near that geographic object? & 5. to position with respect to other objects \\
\hline What is the distance to similar/other objects? & 6. to define relative / absolute distance \\
\hline Is that geographic object linked to other objects? & 7. to encounter spatial linkages \\
\hline Why is a geographic object there? & 8. to explain a location \\
\hline What is the spatial distribution of that object? & 9. to find order, patterns or spatial anomalies \\
\hline Where is the most / least? & 10. to quantify spatial anomalies \\
\hline Where are the limits of a spatial distribution? & 11. to delimit a distribution \\
\hline What comes in / what goes out? & 12. to connect a region to the outside world \\
\hline \multicolumn{2}{|l|}{ Temporal } \\
\hline Has that geographic object always been there? & 13. to determine changes \\
\hline Have the spatial distribution patterns changed? & 14. to establish trends \\
\hline Which spatial processes are taking place? & 15. to detect processes \\
\hline \multicolumn{2}{|l|}{ Overall } \\
\hline What are the influences from outside the region? & \\
\hline What relevant patterns are there? & 17. to recapitulate the found patterns \\
\hline Are there relationships between spatial patterns? & 18. to discover correlations / dependencies / conflicts \\
\hline Which factors cause the regional structure? & 19. to structure the geographic information \\
\hline Can different (sub-)regions be identified? & 20. to regionalize \\
\hline What are the region's geographic characteristics? & 21. to obtain insight into and overview of the region \\
\hline
\end{tabular}

Table 1. Geographic questions and tasks on map reading process (Source: Van Elzakker, 2004)

For the test, a website containing a questionnaire translated into Portuguese, English and Polish was created, and e-mails containing invitations to discussion groups and research groups were sent out. On the site, the volunteers ac-cessed the questionnaire with questions divided into two parts: the volunteer's characterization in relation to their level of training and habits of use of topographic map, and a second group of questions that constitute tasks on the common use of topographic maps (Figure 2). The mechanics of the test were a web form and, therefore, the efficiency in terms of get back to previous questions, or the time the user took to answer each question, was not evaluated. It is impossible to properly determine the response time in a remote web environment, especially because there is no security of 
the user's exact behaviour. On the other hand, in real situation of use it is exactly in this environment that this user would be visualizing and interacting with a map.

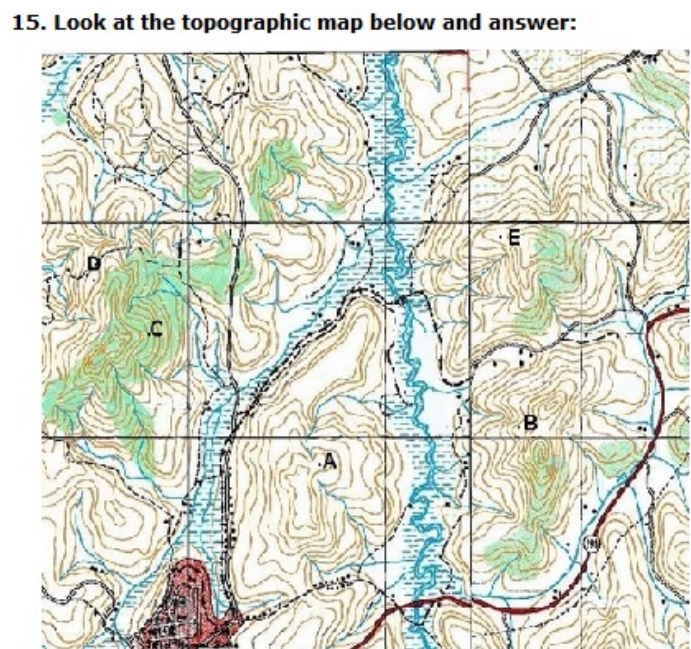

15a) In the map above, which of these points are further away?

$$
\begin{aligned}
& \text { a) Points A, C } \\
& \text { b) Points B, D } \\
& \text { c) Points A, B } \\
& \text { d) Points B, C } \\
& \text { e) Points A, D } \\
& \text { 15b) What are these } \\
& \text { a) Points A, C } \\
& \text { b) Points B, D } \\
& \text { c) Points A, B } \\
& \text { d) Points A, C, D } \\
& \text { e) Points A, B, D } \\
& \text { Next }
\end{aligned}
$$$$
\text { 15b) What are these points further north over the main highway? }
$$

Research Team of cartography users - testescartografia at gmail.com

Fig. 2. Example of questions using Brazilian Map. Source: Authors

The 14 questions of the first group sought to determine a profile of participants in relation to the criteria for map utilization, training in cartography, participation in the production of topographic and thematic maps, age, sex, formal training in cartography and other aspects that may have correlation with the performance in the map reading process. In addition, the nationality of each participant was requested, and confirmed by the choice of the language of the website. This nationality was assumed as familiarity with the map symbology. Regarding preference, prior to the questions that establish the effectiveness of the analysis, the user was asked to answer the preference regarding an extract from a Polish map and an extract from a Brazilian map, having to choose one of the two as preferred and justify the choice.

The 16 questions of the second group included aspects about auto-localization, distance estimation and evaluation of internal orientation, representation of reference points, existence of features in the short-term memory of the volunteers. This group of questions is related to the measurement of the effectiveness of cartographic representation.
For this, the questions contained extracts from the topographic maps of Brazil and Poland and questions associated with reading specific symbols and questions about map interpretation. These questions were drawn from common cases of map use and each contained five response alternatives, which the participant should choose. Examples of reading questions are: "Which points are further north from the highway?"; The questions about interpretation and reasoning included: "Which of the following points are in the same river basin?" Thus, each question in this group, except for preference in relation to symbology, has a template.

After presenting each extract and answering the questions, different sketches were presented (Figure 3) to evaluate the understanding and memorization of the cartographic representation besides the preference of the volunteers in relation to the symbology adopted. At this stage, the topographic map of Figure 2 was no longer visible, but only the sketches, and the volunteers should report which of these presented the closest resemblance to the map just observed in terms of the distribution of features and completeness of information. All questions have an open space where users could comment and justify their responses as a way to help in understanding the strategies and motivations of users. However, as this study is preliminary, the analyses sought to focus on the effectiveness aspect, keeping the discussion of cognitive strategies to a later stage.
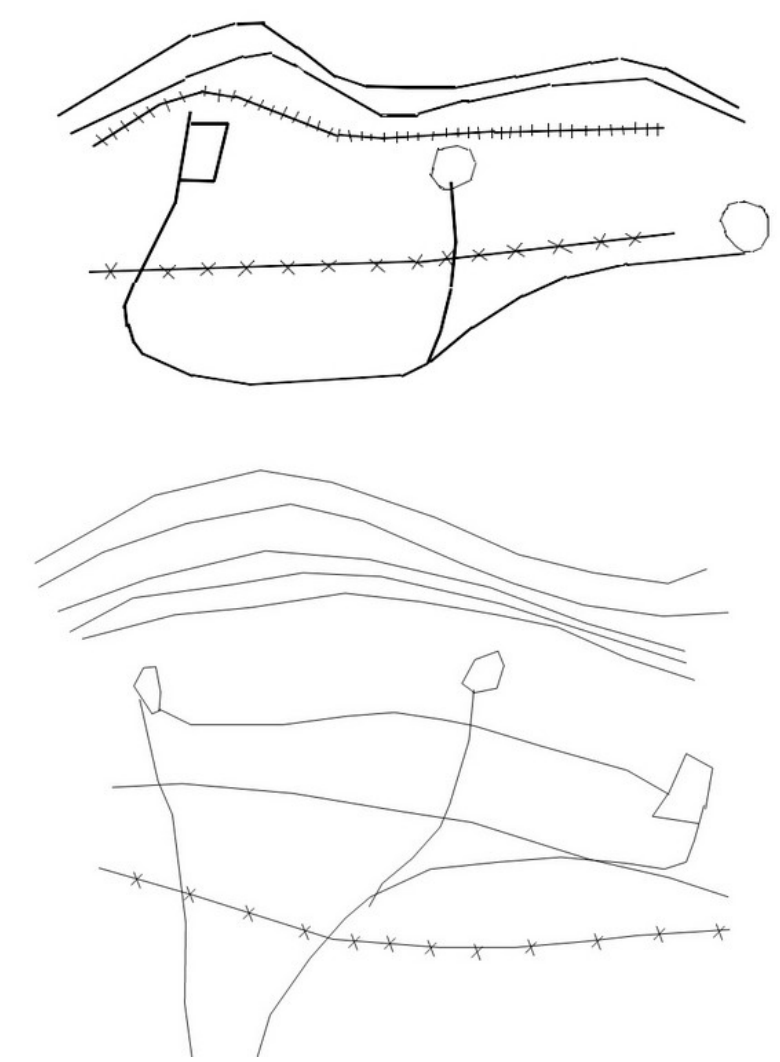

Fig. 3: Example of sketch used in the tests based on the topographic map of Poland. Source: Authors 


\section{Results and discussions}

The valid tests were counted on a total of 53 participants, containing undergraduate students, professors and graduate students in Brazil and Poland. The average profile of the sample corresponds to upper-level users, in areas such as cartography and geography, which use maps with some frequency (Figure 4).

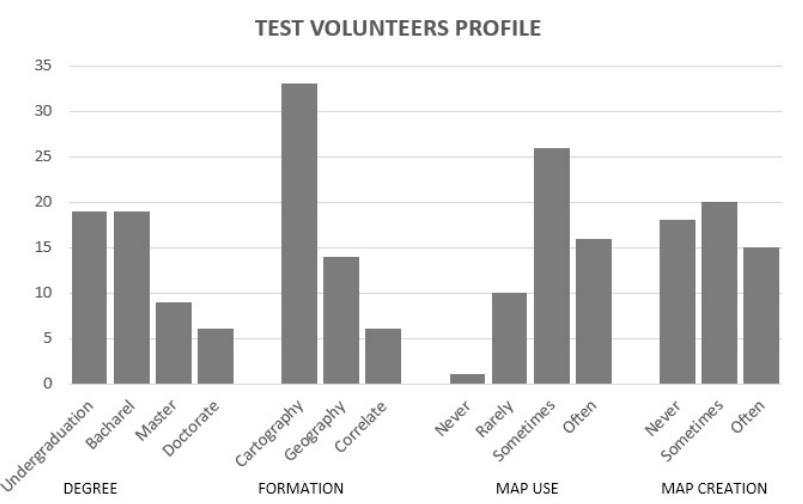

Fig. 4: Characterization of volunteers profile. Source: Authors

The answers given were stored in a database for nonparametric analysis of variance using Kruskal-Wallis test at a significance level of $5 \%$. The test compared the frequencies collected from participants' responses using maps of their own country and then using maps from another country. The responses were correlated with the characteristics of the users, such as formal training degree, training area and other answers to personal profile questions. Results of correlation of responses (efficacy) with the nationality / familiarity factor are shown in Table 2.

\begin{tabular}{|c|c|c|c|c|}
\hline \multirow{3}{*}{$\begin{array}{l}\text { Geograp } \\
\text { hic Task }\end{array}$} & \multicolumn{4}{|c|}{ Kruskall-wallis tests (5\%) } \\
\hline & \multicolumn{2}{|c|}{$\begin{array}{c}\text { Brazilia } \\
\mathrm{n} \\
\text { Volunte } \\
\text { ers }\end{array}$} & \multicolumn{2}{|c|}{$\begin{array}{c}\text { Polish } \\
\text { Volunte } \\
\text { ers }\end{array}$} \\
\hline & $\begin{array}{c}\mathrm{p} \\
\text { (Brazilia } \\
\mathrm{n} \text { maps) }\end{array}$ & $\begin{array}{c}\mathrm{p} \text { (Polish } \\
\text { maps) }\end{array}$ & $\begin{array}{c}\mathrm{p} \\
\text { (Brazilia } \\
\mathrm{n} \text { maps) }\end{array}$ & $\begin{array}{c}\mathrm{p} \text { (Polish } \\
\text { maps) }\end{array}$ \\
\hline $\begin{array}{c}\text { Altitude } \\
\text { estimatio } \\
n\end{array}$ & 0.0405 & 0.1577 & 0.0011 & 0.0001 \\
\hline $\begin{array}{c}\text { Intervisib } \\
\text { ility } \\
\text { between } \\
\text { points }\end{array}$ & 0.0429 & 0.1022 & 0.0181 & 0.0209 \\
\hline $\begin{array}{l}\text { Watershe } \\
\mathrm{d} \\
\text { identificat } \\
\text { ion }\end{array}$ & 0.8644 & 0.0649 & $\begin{array}{c}4.727 \mathrm{e}- \\
05\end{array}$ & 0.0049 \\
\hline $\begin{array}{c}\text { Distance } \\
\text { estimatio } \\
n\end{array}$ & 0.0586 & 0.1263 & 0.0198 & 0.1737 \\
\hline
\end{tabular}

Table 2. Degree of significance of the kruskal-wallis test (5\%) based on the comparison of the reading of Brazilian and Polish topographic maps

The results demonstrate that the result was completely effective for volunteers with high formal training (15 volunteers with master / doctoral degree). That is, for both the reading and interpretation tests this group obtained $100 \%$ responses with answer key. Formal training seems to be the only variable with a positive influence on the performance of volunteers. The Polish volunteers had a positive correlation to understand the watershed limits and the intervisibility between points. The numbers also indicate that Brazilians have a positive response to the reading of contour lines with Brazilian maps in comparison to the use of Polish maps. The test would need to have similar size of samples so that differences between the performance of both groups could be asserted, but the height and point intervisibility estimates show positive significance for both groups using Brazilian topographic maps, but not when using Polish maps.

Evaluating tasks that involve reasoning beyond map reading requires an adequate testing project for such a consideration from user training to the design of tasks that require multi-stage memory and symbology comparison processes. In the present study, the tasks of relative orientation and association of the features represented in the sketches with the newly observed maps generated negative results. This means that such analyses were performed incorrectly in more than $50 \%$ of the cases, besides this result had no positive correlation with none of the other featured. It is worth mentioning that because it was a test through internet there was no time control and for this rea-son, some users may not have dedicated adequate time to carry out the evaluation of the maps.

When evaluating the relationship between preference and performance corroborate Mendonça and Delazari (2014) and Hegarty et al. (2009), whose results demonstrate that user preferences are not necessarily linked to more effective performance. Users justified their preference by considering not only familiarity, but also by the belief of what would be most effective in obtaining a better result. Some of the answers cited as reasons the characteristics of the symbology related to the use of colours as well as those that provided, in the opinion of the user, "a better distinction of the mapped features". Other comments included the choice of colours for symbology, which would make maps easier to read. To these characteristics of the maps, many volunteers associated a concept of readability of the same. In other words, for Brazilians the IBGE maps are more readable and for the Poles IGIK maps are more readable.

\section{Conclusions}

We analysed only one aspect of the culture that is the formal training and, in an exploratory way, the influence of the use of maps with which the users are familiar. Due to the correlation of the number of positive results in relation to the answer key, the results indicate that high levels of formal training positively influenced the reading and interpretation results of the map presented in the test. This analysis was declaratory, that is, through questionnaires answered by the internet and the correlations found, although valid, need to be expanded 
and tested again with a larger and more representative sample to ensure the consistency of these results.

This study also shows that there is no evidence that expert users using maps of their own country have significantly better results when using maps produced in an foreign country, but users prefer their maps. The results also show a low correlation between subjective preference and performance measured for map reading tasks. This points to the need to plan specific tests for mapping reasoning tasks given the dynamic character of the internet and the lack of real appeal for purely scientific assessments. Maps are always used in specific contexts and for the correct evaluation of their potential for reasoning the type of environment must be reproduced in usability tests.

The authors emphasize that this research has an introductory character and emphasizes the need for studies with greater amplitude, especially with the greater number of participants from other countries. It is also recommended that these studies seek to apply different visual solutions to the symbology of the map and tools of interactivity in order to evaluate broader aspects of interpretation and use of cartographic representation.

\section{Acknowledgements}

We are grateful to Prof. Wang Tao from The Future Cities Laboratory. Cingapura - ETH Center for Global Enviromental Sustenta-bilidade. for your valuable contribution to the initial discussions of the project. This research is supported by the $\mathrm{CNPq}$ pelo Edital Universal $04 / 2012$.

\section{References}

Crampton, J. W. (2001). Maps as Social Constructions: Power, Communication and Visualization. Progress in Human Geography. 25, pp. 235-252. Avaiable at: http://www.praxis-epress.org/CGR/35-Crampton.pdf. Accessed in: 12/02/2015

Goodledge. R. G. (1993). Do People Understand Spatial Concepts: The Case of First-Order Primitives. Working Paper UCTC No. 211. Available at: http://www.uctc.net/papers/211.pdf. Accessed in 12-012011.

Hegarty. M.. Smallman. H.S.. Stull. A.T.. Canham. M. (2009) "Nave Cartography: How Intuitions about Display Configuration Can Hurt Performance." Cartographica. vol.44. N3. pp 171-86. DOI:10.3138/carto.44.3.171

Issmael. L. S. (2008). Cartografia Cognitiva: Um Instrumento de Espacialização de Informações Geográficas. Rio de Janeiro: Universidade Federal do Rio de Janeiro. Programa de Pós-graduação em Geografia. 270p. Thesis (PhD) - Universidade Federal do Rio de Janeiro. Programa de Pós-graduação em Geografia.

Ito K. \& Sano Y. (2011). Cultural differences in the use of spatial information in wayfinding behavior. Anais da 25th International Cartographic Conference París. Avaiable
http://icaci.org/files/documents/ICC_proceedings/ICC2 011/Oral\%20Presentations $\% 20$ $\mathrm{PDF} / \mathrm{B} 2-$ Usability\%20evaluation/CO-096.pdf

Keates. J. (1996). Understanding Maps. 2. Ed. Longman.

Lee. M.. \& Butler. B. S. (2014). "I know where that is": Cultural Differences in Perception of New Places. iConference 2014 Proceed-ings (p. 1096-1100). doi:10.9776/14390. Avaiable at:

https:/www.ideals.illinois.edu/bitstream/handle/2142/4

7358/390_ready.pdf? sequence $=2$

Lobben. A.K. (2004). Tasks. Strategies. and Cognitive Processes Associated With Navigational Map Reading: A Review Perspective. The Professional Geographer. 56(2). pp 270-281. Association of American Geographers. Blackwell Publishing. Avaiable at: http:/geography.uoregon.edu/geocog/information/librar y/ lobben_04_tasks.pdf. Accessed in: 25-01-2011

Lloyd.R.E. \& BUNCH. R.L. (2005). Individual differences in map reading spatial abilities using perceptual and memory. Cartography and Geographic Information Science. Available at: http://findarticles.com/p/articles/mi_hb3006/ Accessed in 02-02-2011.

Mendonça. A.L.A. de. \& Delazari. L.S. Testing Subjective Preference and Map Use Performance: Use of Web Maps for Decision Making in the Public Health Sector. Cartographica. V. 49. N2. pp 114-126. 2014. University of Toronto Press. DOI: 10.3138/carto.49.2.1455

Maceachren, A. 1995. How Maps Work: Representation, Visualization and Design. ISBN 0-89862-589-0. Guilford Press, United States.Mondschein. A.. Blumenberg. E.. Taylor. B.D. (2005). Cognitive mapping. travel behavior. and access to opportunity. Anais: Presentation at 85th Annual Meeting of the Transportation Research Board. 2005. Available at: www.uctc.net/papers/753.pd Accessed in 12-01-2011

Montello D.R. (2002). Cognitive Map-Design Research in the Twentieth Century: Theoretical and Empirical Approaches. Cartography and Geographic Information Science. V 29. N3. pp 283 -304. 2002. Available at: www.geography.wisc.edu/

histcart/v6initiative/12montello.pdf Accessed in 23-112010 .

Montello. D. R. \& XIAO. D. (2011). Linguistic and Cultural Universlity of the Concept of Sense-ofDirection. M. Engenhofer et al. (Eds.): COSIT 2011. LNCS 6899. pp. 264-282. 2011. Sprnger-Verlag Berlin Heidelberg.

Nisbett, R.E. \& Miyamoto, Y. (2005) The influence of culture: holistic versus analytic perception. TRENDS in Cognitive Sciences Vol.9 No.10. Elsevier. doi:10.1016/j.tics.2005.08.004

Olson. J. (1976). A Coordinated approach to Map Communication Improvement. The American Cartographer. Vol. 3. n. 2. p. $151-159$. 
Perkins. C. (2004). Progress in Human Geography Vol. 28. n.3. pp. 381 -391. DOI: 10.1191/0309132504ph504pr. Avaiable at: : http://phg.sagepub.com/content/28/3/381

Perkins. C. (2009). Performative and Embodied Mapping. Performative encyclopaedia. University of Manchester. Manchester. UK. 2009 Elsevier Inc. Avaiable at: http://culturemap.org.au/sites/all/files/Performative_enc yclopaedia.pdf

Pinker. S. (2009) Como a Mente Funciona. (How Mind Works - Brazilian Edition) 2nd ed. Companhia das letras. 2009. ISBN 978-85-7164-846-3

Roth. Robert E. (2015). Challenges for Human Subjects Research in Cartography. White paper. ICA Workshop on Envisioning the Future of Cartographic Research. August 21. Curitiba. Brazil.

Schmidt. M.A.R \& Delazari. L.S. (2013). Gestalt aspects for differentiating the representation of landmarks in virtual navigation. Car-tography and Geographic Information DOI:10.1080/15230406.2013.807031

Slocum, T. Thematic Cartography and Visualization. 1.ed. New Jersey: Prentice-Hall,1999. pp. 293Tayeb. M. (2001). Conducting Re-search Across Cultures: Overcoming Drawbacks and Obstacles. Anais: International Journal of Cross Cultural Management. 1: 91. $\quad$ DOI: $\quad 10.1177 / 147059580111009$. http://ccm.sagepub.com/content/1/1/91

Van Elzakker.C. P. J.M. (2004). The use of maps in the exploration of geographic data. (Thesis). Koninklijk Nederlands Aardrijkskundig Genootschap/ Faculteit Geowetenschappen. Universiteit Utrecht / International Institute for Geo-Information Sci-ence and Earth Observation. ISBN 90-6809-357-6. Labor Grafimedia b.v. - Utrecht. Holanda. Avaiable at: : http://www.itc.nl/personal/elzakker Acessado em: 1212-08. 